\title{
ARIE FLORESTA DA CICUTA (RJ): UNIDADE DE CONSERVAÇÃO PÚBLICA OU PRIVADA?
}

Daniele Rodrigues Barbosa ${ }^{1}$

\section{Resumo}

A Área de Relevante Interesse Ecológico (ARIE) Floresta da Cicuta localizada na Fazenda pertencente à Usina Presidente Vargas - CSN, Volta Redonda/RJ, antes estatal e agora privada, abriu precedente para uma nova contextualização às mudanças que podem ocorrer nas áreas protegidas. A presente pesquisa mostra essa mudança por meio de dados secundários e pesquisa bibliográfica sobre a unidade de conservação. A finalidade é apresentar informações sobre o uso público antes e após a sua "privatização". Ao final do estudo foi realizada uma análise sobre as competências dos órgãos públicos e privados na unidade de conservação nos períodos anterior e posterior à privatização da Usina Presidente Vargas.

Palavras-chave: Área de Relevante Interesse Ecológico; privatização; uso público

\begin{abstract}
The Area of Ecological Interest (ARIE) Floresta da Cicuta is located in the farm belonging to the Presidente Vargas Steelworks - CSN, Volta Redonda / RJ, before state and now private. This fact opened precedent to a new context to the changes that may occur in protected areas. This research shows that change through secondary data and literature about that protected area. The purpose is to provide information about public use before and after the "privatization". At the end of this study was an analysis of the skills of public and private agencies in the conservation unit in the periods before and after the privatization of the Presidente Vargas Steelworks.
\end{abstract}

Keywords: Area of Relevant Ecological Interest; privatization; public use

\section{Introdução}

A Área de Proteção Ambiental Floresta da Cicuta, localizada entre os municípios de Volta Redonda e Barra Mansa, no estado do Rio de Janeiro, foi criada em 1985. A área pertenceu à União até a privatização da Companhia Siderúrgica Nacional em 1993. Este fato fez com que a Fundação CSN assumisse a responsabilidade pela gestão da Fazenda e, consequentemente, da sede e do seu interior, onde está situada a atual Área de Relevante Interesse Ambiental (ARIE) Floresta da Cicuta. Em relatórios anuais, a empresa enfatizava a visitação constante para o lazer dos moradores e o contato com a unidade de conservação, até o momento em que foi fechada sem maiores justificativas à população.

\footnotetext{
${ }^{1}$ Mestranda em Tecnologia Ambiental na Universidade Federal Fluminense - Escola de Engenharia Industrial e Metalúrgica de Volta Redonda.biologiavr@yahoo.com.br
} 
Um grupo de moradores organizados exigiu providências do órgão ambiental quanto ao fechamento do acesso à unidade de conservação, que se dá pelo interior da Fazenda Santa Cecília. Com apoio do Ministério Público, foram impetradas ações que resultaram no estabelecimento da sede provisória, da indicação do chefe responsável pela unidade de conservação - funcionário do ICMBio - e o cumprimento do Termo de Ajustamento de Conduta (TAC) pela CSN. Depois dessas providências a unidade de conservação foi incluída no Programa de Voluntariado do ICMBio, objeto da presente pesquisa, desenvolvida no período de junho a dezembro de 2012.

Atualmente, o acesso pela Fazenda até o interior da unidade é restrito aos pesquisadores e grupos de estudantes com orientação docente e com a ciência da empresa proprietária das terras.

O objetivo do presente artigo é apresentar o histórico de criação da referida ARIE, incluindo os instrumentos legais associados, e a polêmica envolvendo a relação entre a CSN, o ICMBio, a mobilização popular e a intervenção do Ministério Público Federal no intuito de consolidar a unidade de conservação. Também será apresentado o quadro atual de gestão e uso público da área, incluindo suas contradições.

O trabalho foi desenvolvido com apoio de pesquisa bibliográfica e consulta em fontes de dados secundários, além do emprego de pesquisa documental e legal pertinente à unidade de conservação, aos órgãos e à empresa envolvidos na sua gestão.

\section{ARIE Floresta da Cicuta: criação, localização e instrumentos legais}

A inserção do setor privado na produção de serviços públicos tem se tornado comum segundo Fadul (1997). Venda dos ativos públicos a empresas privadas, transformação de administrações públicas em sociedades de economia mista, delegação através de contratos de prestação de serviços, concessão, permissão, terceirização ou parceria, são expressões comumente utilizadas pelos administradores públicos de qualquer esfera de governo. As mudanças nos modelos de gestão dos serviços públicos locais podem pôr em risco o conteúdo do que vinha sendo considerado até então como público, hoje sendo dissociada do domínio público. Com isso o poder público e o cidadão podem estar perdendo, respectivamente, seus meios de controle, de livre acesso e de utilização de grandes parcelas de espaço público, justamente aquelas que correspondem aos espaços urbanos mais dinâmicos de acordo com Fadul (1997).

A reforma administrativa, a coordenação entre as diferentes agências, a presença de funcionários bem treinados e a redução de conflitos com a população local são aspectos políticos-institucionais que devem ser abordados no plano de manejo de uma unidade de conservação, segundo Morsello (2001). Encontrar áreas protegidas e suas zonas de influência sob a responsabilidade de diferentes instituições do governo, ONG's e grupos particulares é comum e este fato tem levado à necessidade de cooperação entre diferentes agências de governo e outras instituições. Uma das principais mudanças necessárias ao manejo é a de incrementar a capacidade de resolver conflitos interinstitucionais e os governos devem manter 
um papel central na gestão de unidades de conservação, mesmo nas economias mais privatizadas (BARBORAK, 1995 apud MORSELLO, 2001).

A Lei $\mathrm{n}^{\circ} 9.985$ de 2000, referente ao Sistema Nacional de Unidades de Conservação SNUC - dispõe, em seu artigo $28^{\circ}$, que até a elaboração do plano de manejo de todas as atividades, deve se limitar à destinação que não comprometa a integridade dos recursos que a área protegida. A ARIE é uma unidade de conservação de Uso Sustentável e, segundo a mesma lei, está sujeita às mesmas normas estabelecidas para unidades de proteção integral. As unidades de conservação de Proteção Integral, segundo artigo $29^{\circ}$ do SNUC, devem dispor de um Conselho Gestor, "presidido pelo órgão responsável por sua administração e constituído por representantes de órgãos públicos, de organizações da sociedade civil". A unidade de conservação, mesmo sendo de Uso Sustentável, deve possuir um Conselho Gestor. $\mathrm{O}$ artigo trigésimo cita que as unidades de conservação podem ser "geridas por organizações da sociedade civil de interesse público com objetivos afins aos da unidade, mediante instrumento a ser firmado com o órgão responsável por sua gestão".

O nome Cicuta vem de uma planta aquática comum na região, da família Hydrocharitaceae (CSN, 1999). A Fazenda Santa Cecília , segundo Lima (2004), era parte da Fazenda Três Poços que, depois de proprietários, foi desmembrada e adquirida por Nelson Marcondes Godoy em 1932. Suas terras foram desapropriadas em 1941 para a construção da Usina da Companhia Siderúrgica Nacional (CSN) e a Vila Operária. A atual localização, segundo Costa (2004), inclui os municípios de Barra Mansa e Volta Redonda, do bairro Santa Inês até o Córrego Brandão, seguindo a poligonal original definida pela Lei $\mathrm{n}^{\circ} 2.435$, de 05 de abril de 1955. A Fazenda Santa Cecília foi declarada Área de Relevante Interesse Ecológico pelo Decreto $n^{\circ}$ 90.792, de 09 de janeiro de 1985 e, após a privatização em abril de 1996 da Usina Presidente Vargas/CSN, a propriedade Fazenda Santa Cecília foi privatizada e, consequentemente, o seu interior onde está a ARIE. As delimitações geográficas são ao norte e a leste da unidade de conservação limítrofes à Fazenda Santa Cecília, possuindo área total de 131,28 ha, segundo decreto de criação. Costa (2004) cita a Floresta da Cicuta como última amostra intacta de Mata Atlântica no Vale do Paraíba do Sul. A unidade de conservação esta incluída na lista da Reserva da Biosfera da Mata Atlântica do Estado do Rio de Janeiro (RAMBALDI, 2003)

Em 1985, segundo Costa (2004), a ARIE foi efetivada na forma de Lei Municipal (Volta Redonda) n².016, pelo Decreto Executivo $n^{\circ} 1.964$ e pelo Decreto Federal $n^{\circ} 90.792$. A Lei Municipal incluiu a ARIE no Banco de Preservação Genética da Natureza de Volta Redonda. O Decreto Executivo regulamentou a aplicação da Lei criada e o Decreto Federal dispôs sobre a declaração de ARIE. A abertura de estrada na unidade, segundo o Artigo $3^{\circ}$ do decreto da criação da ARIE, dependerá de aprovação do Presidente da República. Até a privatização, segundo o Artigo $6^{\circ}$, a unidade era supervisionada, administrada e fiscalizada pela Secretaria Especial do Meio Ambiente - SEMA, do Ministério do Interior, em articulação com a Companhia Siderúrgica Nacional (proprietária das terras) e a Prefeitura Municipal de Volta Redonda, além do Estado do Rio de Janeiro (Figura 01). 


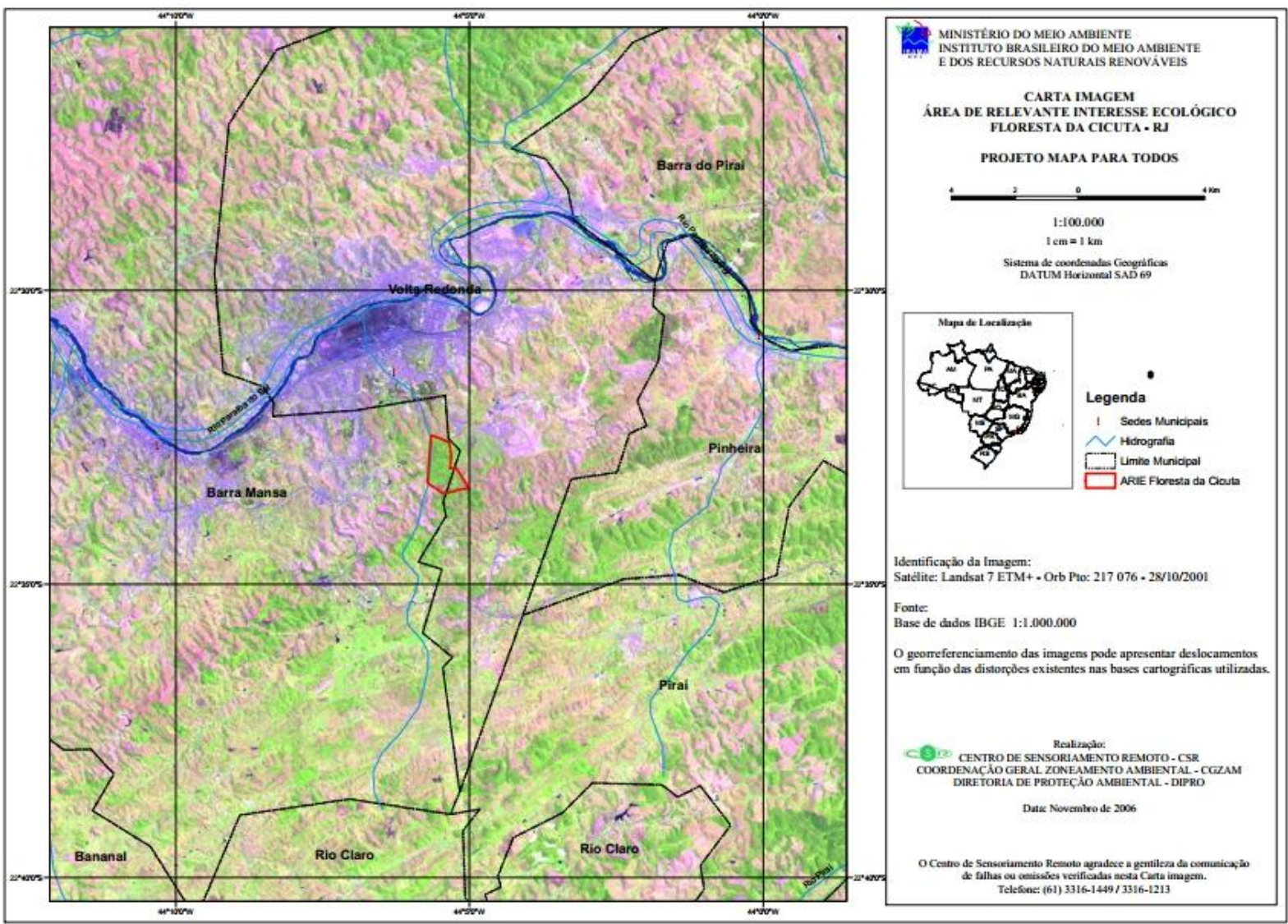

Figura 01. Localização da ARIE Floresta da Cicuta. Fonte SISCOM/IBAMA, 2006.

O Executivo Municipal anunciava em 20 de janeiro de 1990, na edição no 875 do Jornal do Vale, a construção de uma grande represa na Floresta da Cicuta, gerando uma ofensiva pela Associação de Biologia contra o projeto da firma paulista Hidroconsult (COSTA, 2004). Alegou-se que causaria um impacto de grandes proporções no ecossistema local. O autor cita que o local em questão foi declarado área de lazer em meados dos anos 70 e, na década de 80 , a floresta serviu de palco para manobras militares realizadas por soldados do $22^{\circ}$ BIMTz. Depois que foi declarada como ARIE, colocou-se uma placa comemorativa na entrada de uma das duas trilhas que conduzem à Floresta da Cicuta, registrando-se a mudança. No local foram identificados cágado-de-hoge e bugio ruivo, espécies que já estão praticamente extintas das florestas brasileiras (COSTA, 2004).

A privatização da CSN considerou não apenas a venda da usina em si, mas abrangeu todos os imóveis que pertenciam à indústria, incluindo também a Fazenda no centro da cidade limítrofe à ARIE. Quanto à privatização, Andrade (2001, apud. Baptista ; Saraiva, 2005) declara que algumas empresas, antes do processo de privatização, cederam aos municípios e/ou puseram à venda, imóveis pertencentes às mesmas, a exemplo da Acesita no município de Timóteo, em Minas Gerais. 


\section{A CSN e a Unidade de Conservação}

O relatório anual da CSN de 1999, onde consta o balanço social e ambiental da empresa, relata que na Cicuta a área de recreação foi entregue à população de Volta Redonda em 1999. Descreve que antes "aquilo tudo era mato puro" e, com investimentos de R\$600 mil, a Fundação CSN transformou o entorno da antiga sede da Fazenda Santa Cecília num dos pontos mais atrativos da cidade com playground, pista de 600 metros para corridas e caminhadas, passarela sobre o lago e área de repouso com sanitários. O relatório cita comentários de usuários da Fazenda Santa Cecília, que “já incorporaram à sua rotina frequentar a Fazenda em busca de contato com a natureza." O relatório enfatiza da carência de áreas verdes no perímetro urbano e que o resgate desse espaço equivalia "a uma verdadeira dádiva.” A Fazenda recebia semanalmente cerca de 2.000 adultos e 700 crianças. Em pesquisa realizada em 1998 pelos técnicos da Fundação Brasileira para o Desenvolvimento Sustentável (FBDS) para a CSN, foi questionado o que atraía os 150 usuários à Fazenda e as respostas predominantes foram: ar puro (62\%) e tranquilidade (24\%).

A Fundação CSN era a responsável pela sua preservação e investia para torná-la acessível a toda a comunidade, transformando-a em centro de eventos culturais e educação ambiental. Havia a pretensão de um Plano de Uso que permitiria a utilização racional do entorno com atividades científicas, ecológicas e educativas. Quando se tornou propriedade da CSN, o lugar foi usado para o lazer dos empregados, mas permaneceu fechado aos demais moradores de Volta Redonda. O relatório cita banho nas cachoeiras formadas pelos córregos Brandão e Brandãozinho (ex-Cachoeirinha), que cortam a floresta. Os dois rios eram temas de um estudo da Fundação CSN para a melhoria da qualidade de suas águas.

A Fundação CSN considerou transformá-la num santuário ecológico, exercendo a vigilância em espaço tão amplo e considerou pendente a fixação de critérios para que os visitantes conhecessem a floresta, sem danificá-la. E declarou que, até que se organizem as formas de acesso e se implantem sistemas de controle, o ingresso à floresta estaria interditado a não ser para pesquisadores. Informou, em 1999, a existência de um dossiê da FBDS sobre a constituição ecológica da Reserva, com instruções detalhadas de uso. Consolidados os sistemas de proteção, segundo relatório ambiental da CSN de 1999, a floresta estaria aberta à visitação. A área de recreação inaugurada no ano de 1998 na parte de fora da floresta, seria ampliada com a instalação de novos equipamentos. No ano 2000 seriam construídos ali um mini museu, um auditório e um restaurante - incluindo relógio de sol, concha acústica, paredão para escaladas, viveiros para aves nativas e produção de mudas. O objetivo era transformar a Cicuta num espaço destinado ao lazer, à cultura e aos estudos ecológicos.

Os aspectos políticos-institucionais vistos no trabalho de Carvalho et. al. (2009), intitulado "CSN e Responsabilidade Socioambiental: Conscientização, Estratégia ou Necessidade?" relacionavam as atividades da empresa e seus investimentos na área ambiental. O trabalho não incluiu diretamente atividades, planos e/ou investimentos na Fazenda Santa Cecília e ARIE Floresta da Cicuta. A gestão ambiental, segundo os autores, começou a ser efetivamente realizada pela empresa após a privatização e havendo indicadores metas e TAC's em processo de negociação e efetivação. $\mathrm{O}$ meio ambiente era um ponto de destaque 
nas ações sociais da Fundação CSN, não apenas pelo expressivo montante destinado a essa área (aproximadamente 2,360 milhões de reais), mas também pelo fato das ações ultrapassarem a região de localização da empresa. Faziam parte das ações aulas de jardinagem com noções de ecologia, silvicultura, jardinagem e paisagismo, para adolescentes da rede municipal de ensino de Volta Redonda. Havia o Projeto Jovens Jardineiros e a implantação de um moderno centro de lazer voltado para atividades de preservação do meio ambiente em Volta Redonda e Barra Mansa denominado Projeto Cicuta (EXAME, 2000 apud BAPTISTA ; SARAIVA, 2005).

\section{A atuação do ICMBio}

A gestão de unidade de conservação pelo órgão federal é detalhada na publicação do ICMBio (2011), onde se observa que havia possibilidades de interloução entre agentes de cooperação, a iniciativa privada e a esfera pública no plano de manejo (Figura 02).

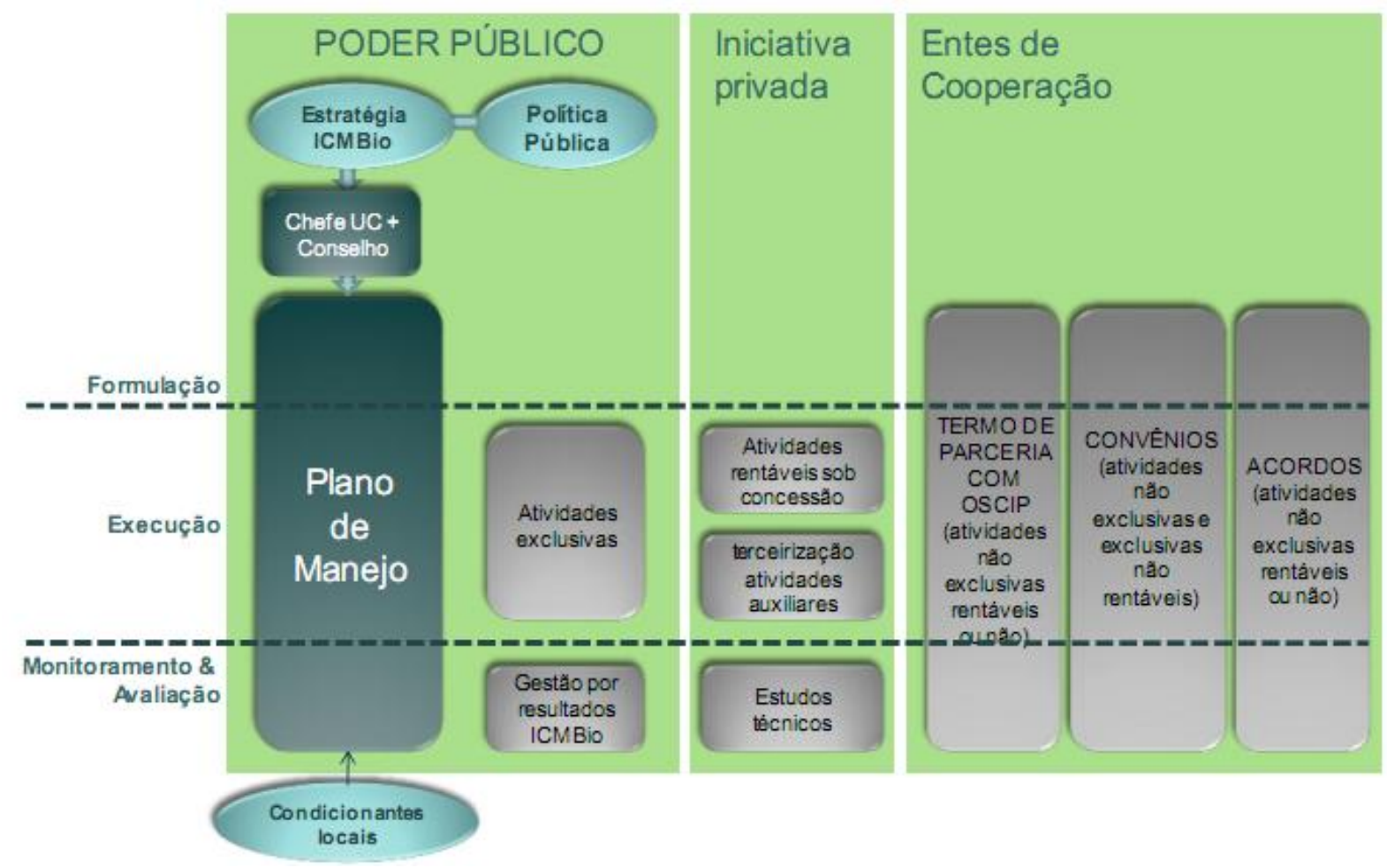

Figura 02. Delimitação de campos de atuação do Estado, da iniciativa privada e dos demais entes de cooperação. Fonte: ICMBio, 2009.

A ARIE possui um Conselho Gestor com a atribuição legal de "acompanhar a elaboração, implementação ou revisão do Plano de Manejo da unidade de conservação, quando couber, garantindo o seu caráter participativo", disposto no inciso I, artigo $20^{\circ}$ do Decreto $n^{\circ} .4 .340$ de 2002. Em Ata de reunião de Conselho realizada no dia 30 de março de 2009, o representante do Ministério Público apresentou documento enviado aos órgãos públicos sobre a situação da unidade de conservação na época, as ações recomendadas e os prazos para a execução das mesmas, incluindo proposta de recategorização de ARIE (uso sustentável) para Refúgio da Vida Silvestre (proteção integral). Foi citada a omissão dos órgãos gestores enumerando os diversos inquéritos administrativos, além da omissão do 
IBAMA e do ICMBio e a falta de plano de manejo e zoneamento. O mesmo documento relata a "precária situação da ARIE da Cicuta chegando ao estado de abandono", sem sede e instrumentos mínimos de trabalho. Este documento priorizou as ações propostas pela Procuradoria do Ministério Público Federal (MPF) aos municípios de Volta Redonda e Barra Mansa que, ao realizarem licenciamento ambiental, observassem as normas contidas no art. $2^{\circ}$ da Resolução do CONAMA no 13 de 1990, no art. 36, §3º da Lei 9.985/00 e na Instrução Normativa do ICMBIO nº 01/2009. No tocante ao ICMBio foi solicitada a designação de um servidor para chefiar a ARIE, instalação de uma sede, efetivação do Conselho Gestor, recategorização da ARIE e elaboração do plano de manejo. No caso da CSN, foi cobrada a celebração de TAC com o ICMBio. Isto foi possível devido à mobilização do Conselho Gestor, conforme a própria Ata. Atualmente a ARIE Floresta da Cicuta possui sede provisória fora dos seus limites, com administrador do ICMBio e funcionários designados por TAC da CSN junto ao órgão federal. Até o momento, é aguardada uma posição da empresa quanto à sede dentro dos seus limites para efetivar projetos de educação ambiental e demais ações.

Uma avaliação da efetividade de gestão realizada pelo ICMBio em 2010, tendo como referência a aplicação do método RAPPAM $^{2}$, confrontou as ações desenvolvidas com as necessidades das unidades de conservação, buscando-se garantir que os seus objetivos sejam alcançados. Esse Método é baseado na aplicação de um questionário contendo cinco elementos do ciclo de planejamento, gestão e avaliação: contexto, planejamento, insumos, processos e resultados, sendo cada elemento é composto por temas específicos, abordados em diferentes módulos temáticos (ICMBio, 2011). Os resultados da avaliação realizada na referida ARIE estão contidos na Tabela I.

Tabela I. Quadro síntese da efetividade de gestão na ARIE Floresta da Cicuta, segundo o Método RAPPAM 2010.

\begin{tabular}{|c|c|c|c|c|c|c|c|c|c|c|c|c|c|c|}
\hline 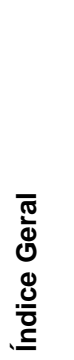 & 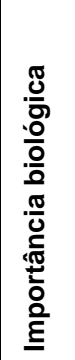 & 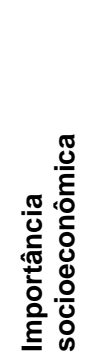 & 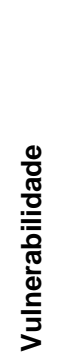 & 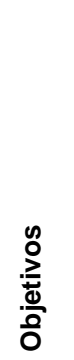 & 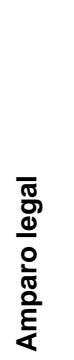 & 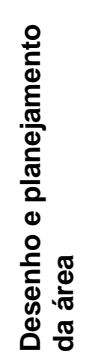 & 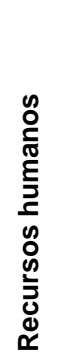 & 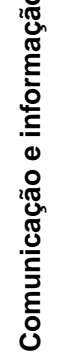 & 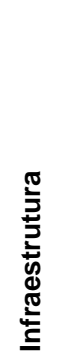 & 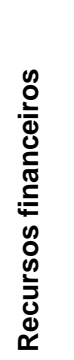 & 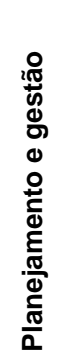 & 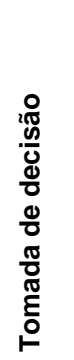 & 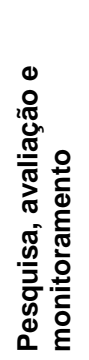 & 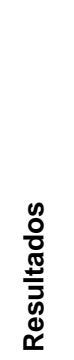 \\
\hline $41 \%$ & $89 \%$ & $22 \%$ & $20 \%$ & $67 \%$ & $52 \%$ & $23 \%$ & $20 \%$ & $83 \%$ & $76 \%$ & $33 \%$ & $20 \%$ & $94 \%$ & $0 \%$ & $20 \%$ \\
\hline
\end{tabular}

Fonte: ICMBio, 2011.

Os dados da tabela indicaram que a ARIE tem uma "importância biológica" elevada (89\%), o que justifica os esforços de conservação da biodiversidade. No plano "socioeconômico", entretanto, o resultado de $22 \%$ indica a necessidade de fortalecer a relação entre a população e o uso público da ARIE. O "amparo legal" de 52\% caracteriza que os instrumentos regulatórios de proteção e uso da área, precisam ser ampliados e consolidados.

\footnotetext{
${ }^{2}$ Método de Avaliação Rápida e Priorização do Manejo de Unidades de Conservação (RAPPAM - Rapid Assessment and Priorization of Protected Area Management)
} 
Apesar de que no item relativo à "tomada de decisão", o valor encontrado foi elevado (94\%), outros itens importantes como "recursos humanos" (20\%), "planejamento e gestão" (20\%), "desenho e planejamento da área" (23\%), "recursos financeiros" (33\%), apresentaram valores baixos. O item de "pesquisa, avaliação e monitoramento" teve a pior avaliação $(0 \%)$, o que justifica a necessidade grandes investimentos nesse setor. A "comunicação e informação" teve elevada pontuação (83\%), indicando que há divulgação da existência da unidade de conservação e seu conhecimento junto ao público, é elevado.

Portanto, os dados indicam que a ARIE tem sua importância reconhecida pelo público, apresenta uma boa infraestrutura física de administração, mas carece de meios (humanos e materiais), além de estratégias de planejamento e gestão pra se consolidar como uma unidade de conservação.

Cabe destacar que o acesso à ARIE é feito, na atualidade, pela Fazenda Santa Cecília, uma propriedade privada, tornando-se uma condição restritiva. Devido a isto e, à não conclusão do plano de manejo, o ICMBio restringe o ingresso apenas aos pesquisadores e grupos de estudantes. Existe a necessidade de um cadastro prévio de duas semanas, onde a unidade de conservação e a empresa tomam ciência das pessoas que visitam e das atividades desenvolvidas. A empresa possui livre acesso à Fazenda, mas no caso das pessoas de fora, há necessidade do acompanhamento de um vigia para abri-la e de comunicação interna sobre sua presença e objetivos. A administração da unidade de conservação é responsável pelo que ocorre no seu interior, assim como as medidas de gestão. Entretanto, suas ações são limitadas pelo controle territorial exercido pela empresa.

\section{Conclusões}

A ARIE e a Fazenda forneciam conjuntamente, uma área de lazer e de educação ambiental, aos moradores e demais visitantes mesmo após a privatização, mas não foi observado o uso público esperado em relatórios de atividades da empresa recentemente.

A unidade de conservação só obteve interferência do órgão público ambiental federal (o ICMBio) após a ação do Conselho Gestor organizado por representantes dos municípios de Volta Redonda e Barra Mansa em conjunto com o Ministério Público Federal. Até a presente data (2013), as construções e usos para lazer, cultura e estudos propostos em relatórios descritos, não foram realizados pela empresa. O problema do acesso à área precisa ser equacionado para facilitar o uso mais abrangente pela população, sem tantas restrições. A questão da recategorização de uma unidade de uso sustentável para proteção integral também deve ser debatida e, talvez, operacionalizada.

Estudos científicos e visitas técnicas escolares, apesar de escassas, são autorizados e incentivados pelo órgão federal ICMBio, que é o responsável pela gestão dentro da unidade de conservação. Um plano de manejo eficiente pode aproximar os moradores da ARIE. A execução de projetos de Educação Ambiental pelo órgão gestor, a parceria público privada e o interesse da empresa proprietária da área do entorno, pode estimular trabalhos interessantes, até mesmo os anteriormente propostos em relatórios elaborados pela própria CSN. 


\section{Agradecimentos}

Agradecimentos ao ICMBio pela oportunidade através do seu Programa de Voluntariado, no período de junho a dezembro de 2012, e aos funcionários da ARIE Floresta da Cicuta pelo apoio no período da realização deste trabalho.

\section{Bibliografia}

BAPTISTA, R. D. G. S.; SARAIVA, L. A. S. As (novas) práticas pós-privatização de atuação comunitária em seis empresas do setor siderúrgico brasileiro. Caderno de Pesquisas em Administração, São Paulo, v. 12, n. 1, p. 1-17, jan./mar. 2005. Disponível em: < http://www.revistas.usp.br/rege/article/viewFile/36506/39227>. Acesso em: 25 ago. 2012.

BRASIL. Decreto no 90.792, de 9 de janeiro de 1985. Dispõe sobre a declaração de área de relevante interesse ecológico, no Município de Volta Redonda, no Estado do Rio de Janeiro, e dá outras providências. Disponível em:< http://www2.camara.leg.br/legin/fed/decret/19801987/decreto-90792-9-janeiro-1985-440611-publicacaooriginal-1-pe.html>. Acesso em: 13 ago. 2012.

Brasil. LEI No 9.985, de 18 de julho de 2000. Regulamenta o art. 225, § 1o, incisos I, II, III e VII da Constituição Federal, institui o Sistema Nacional de Unidades de Conservação da Natureza e dá outras providências. Disponível em:<http://www.planalto.gov.br/ccivil_03/leis/19985.htm>. Acesso em: 13 jul. 2012.

CARVALHO, R. C. S.; TRINTA, J. L.; BACELLAR, F. C. T. CSN e responsabilidade sócio-ambiental: conscientização, estratégia ou necessidade? Cadernos UniFOA. Volta Redonda, ano 4 , n. 10, ago. 2009. Disponível em:

<http://www.foa.org.br/cadernos/edicao/10/41.pdf >. Acesso em: 08 jul. 2012.

COSTA, A. Volta Redonda ontem e hoje. Volta Redonda: Edição comemorativa 50 anos. Editor Jader Costa, 2004. 1 CD-ROM.

CSN. Balanço social e ambiental: 1999. Disponível em: < http://www.mzweb.com.br/csn/web/arquivos/CSN_Annual_BalancoSocialAmbiental1999_po rt.pdf>. Acesso em: 08 ago. 2012.

FADUL, E. M. C.. Redefinição de espaços e papéis na gestão de serviços públicos: fronteiras e funções da regulação social. RAC, v.1, n.1, p. 55-70, jan./abr. 1997. Disponível em: $<$ http://www.scielo.br/scielo.php?pid=S1415-65551997000100004\&script=sci_arttext >. Acesso em: 07 jul. 2012.

LIMA, R. G. S.. Museu virtual a Volta Redonda do café e do leite: 140 anos de história. junho a agosto de 2004. Disponível em:<

http://portalvr.com/cultura/museu/apoio/arquivos/robertoguiao.pdf >. Acesso em: 19 ago. 2012.

ICMBio. Ata $n^{\circ} 01$ de reunião extraordinária de conselho consultivo da Arie Floresta da cicuta referente ao dia dez de maio do ano de dois mil e onze. Centro de documentação, 2012.

ICMBio. Ata $\mathbf{n}^{\circ} 01$ de reunião extraordinária de conselho consultivo da Arie Floresta da cicuta referente ao dia seis de abril do ano de dois mil e onze. Centro de documentação, 2012. 
ICMBio. Ata $n^{\circ} 01$ de reunião extraordinária de conselho consultivo da Arie Floresta da cicuta referente ao dia oito de março do ano de dois mil e doze. Centro de documentação, 2012.

ICMBio. Ata $\mathbf{n}^{\circ} 02$ de reunião extraordinária de conselho consultivo da Arie Floresta da cicuta referente ao dia dezesseis de junho do ano de dois mil e onze. Centro de documentação, 2012.

ICMBio. Ata $n^{\circ} 03$ de reunião extraordinária de conselho consultivo da Arie Floresta da cicuta referente ao dia vinte e seis de julho do ano de dois mil e onze. Centro de documentação, 2012.

ICMBio. Ata $n^{\circ} 04$ de reunião extraordinária de conselho consultivo da Arie Floresta da cicuta referente ao dia seis de outubro do ano de dois mil e onze. Centro de documentação, 2012.

ICMBio. Ata $n{ }^{\circ} 05$ de reunião extraordinária de conselho consultivo da Arie Floresta da Cicuta referente ao dia 02 de dezembro do ano de dois mil e onze. Centro de documentação, 2012.

ICMBio. Avaliação comparada das aplicações do método Rappam nas unidades de conservação federais, nos ciclos 2005-06 e 2010. Instituto Chico Mendes de Conservação da Biodiversidade, WWF-Brasil. Brasília: ICMBio, 2011. 134 p. Disponível em: < http://www.icmbio.gov.br/portal/images/stories/comunicacao/downloads/relatrio\%20rappam \%202005\%20x\%202010\%20-\%20verso\%20integral.pdf>. Acesso em: 13 set. 2012.

ICMBio. Modelagem institucional do Instituto Chico Mendes de Conservação da Biodiversidade: resumo executivo. Brasília, mar. 2009. Disponível em:< .http://www.icmbio.gov.br/intranet/download/arquivos/planejamento_estrategico/documentos _de_orientacao/1_Modelagem_Institucional-Resumo_Executivo.pdf >. Acesso em: 30 set. 2012 .

MORSELLO, C. Áreas protegidas públicas e privadas: seleção e manejo. 2. ed. FAPESP;ANNABLUME, 2001.

RAMBALDI, D. M. et. al. A Reserva da Biosfera da Mata Atlântica no Estado do Rio de Janeiro. Série Estados e Regiões da RBMA, Caderno da Reserva da Biosfera da Mata Atlântica. Rio de Janeiro: CNRBMA, 2003. Disponível em:< http://www.rbma.org.br/rbma/pdf/Caderno_22.pdf>. Acesso em: 24 ago. 2012.

SISCOM/IBAMA. Carta imagem Área de Relevante Interesse Ecológico Floresta da Cicuta RJ. Base de dados IBGE 1:1.000.000. nov. 2006. Disponível em:

<http://siscom.ibama.gov.br/mpt/rj/uc/ARIE_FLORESTA\%20CICUTA_RJ_A3.pdf >. Acesso em: 30 ago. 2012. 